\title{
Anonymous Feedback: A Real-time Feedback to Capture Students' Engagement in Learning Process Anonymous Feedback
}

\author{
Abida Shaheen ${ }^{1 *}$ Fahad Azam², Khurram Irshad ${ }^{3}$ \\ ${ }^{1}$ Department of Pharmacology, Shifa College of Medicine 1 \\ ${ }^{2}$ Department of Pharmacology, Shifa College of Medicine 2 \\ ${ }^{3}$ Department of Physiology, Shifa College of Medicine 3
}

"Corresponding author.Email: abida.scm@stmu.edu.pk

\begin{abstract}
Teachers' evaluation plays a crucial role in strengthening the learning process and curriculum delivery. In some situations, because of the complicated structure of the feedback proformas or the fear of being identified students might not be able to express themselves honestly. Unstructured and anonymous feedback might help resolve the apprehensions and reluctance of students to give true feedback. We conducted a study to compare quantitative and qualitative data obtained through an anonymous and standardized official evaluation system. One hundred and ten medical students of Year III of Shifa College of Medicine participated in our study during an integrated module. We created an anonymous portal on the website www.freesuggestionbox.com and provided its link to the students. We encouraged students to reflect on their learning process throughout the module and provide quantitative feedback on the anonymous portal at the end of the module. Students also provided structured feedback on a standardized official evaluation questionnaire utilizing a 21-items questionnaire and optional comments as per routine for each faculty member. Quantitative and qualitative data of unstructured and anonymous feedback were analyzed and compared with the feedback provided on the official structures feedback proformas. Broad themes after being assessed by authors were assigned codes, commonalities in both feedbacks were analyzed and any new areas highlighted by students were identified. Quantitative data obtained through each feedback was statistically similar. Students provided more information about new learning strategies incorporated in the module on the anonymous portal in comparison to the official structured feedback portal. The total number of comments on the anonymous feedback portal was much higher than the official feedback portal. Anonymous and real-time feedback may influence the way the message is received and processed and may allow faculty to immediately resolve highlighted problems, ensure active participation and reduce insecurities of medical students.
\end{abstract}

Keywords: nudging, behavior, assessment, motivation.

\section{INTRODUCTION}

Teachers' evaluation is an important component of the learning process and plays a crucial role in curriculum delivery; timely feedback allows teachers to reflect on their practices and modify teaching strategies to improve the learning experiences [1]. The presence of a strong teachers' evaluation system in undergraduate medical education plays a critical role in enhancing curriculum delivery and the learning environment [2,3]. Prerequisites of good evaluations systems include simple proformas that allow students to express themselves without fear of being identified and judged on the basis of their feedback. Timely feedback immediately after teaching sessions also contributes positively to the quality of feedback [1-3].

In certain situations, however, students might not provide honest feedback due to multiple reasons; fear of being identified could be one significant hindrance for students to document their honest opinions about the learning environment and strengths and weaknesses of faculty members [4]. Giving feedback on a structured questionnaire might be another drawback of the faculty evaluation system. Most institutions take feedback from students during a specific time period during the academic calendar which may also affect the quality of 
feedback as timely evaluation is a crucial factor for highquality feedback $[4,5]$.

Institutions all over the world allocate resources to improve the faculty evaluation system; in Pakistan, most medical institutions have developed state-of-the-art systems to evaluate the quality of teaching with an intent to enhance the learning environment [6-8]. However, the inability of these evaluation systems to obtain real-time feed with assurance of complete anonymity for students might affect the quality of evaluation. With this background, the current study was designed to compare the conventional official evaluation system with a newly designed anonymous, real-time and unstructured evaluation system on quantitative and qualitative variables.

\section{METHODOLOGY}

One hundred and ten medical students of year III of Shifa College of Medicine participated in our study during an integrated module. We created an anonymous portal on the website www.freesuggestionbox.com and provided its link to the students. We encouraged students to reflect on their learning process throughout the module and provide quantitative feedback on the anonymous portal at the end of the module. Students also provided structured feedback on a standardized official evaluation questionnaire utilizing an 18-items questionnaire and optional comments as per routine for each faculty member. Quantitative and qualitative data of anonymous and structured feedback were analyzed and compared. Broad themes after being assessed by authors were assigned codes, commonalities in both feedbacks were analyzed and any new areas highlighted by students were identified.

The domains of structured feedback proforma for faculty and course evaluation are as follows:

I. Course Content and Organization, II. Student Contribution, III. Learning, Environment and Teaching Methods, IV. Learning Resources, V. Quality of Delivery:

\section{RESULTS}

During the four-week module, quantitative evaluation obtained through both systems was similar and there was no significant difference between the evaluation scores under different domains. Details of the comparison between the quantitative variables of the evaluation on the conventional and the anonymous portal are provided in table 1 .
Eighty-nine comments were recorded on the anonymous evaluation portal in comparison to twentyfive optional comments on the conventional evaluation questionnaire. No significant differences were identified in the informative quality of data between the anonymous and structured evaluation of modules by the students. Description of the number of comments received on the official portal in comparison to the comments categorized under the identified themes are provided in table 2 .

Table 1: Comparison between evaluation scores of structured and anonymous feedback

\begin{tabular}{|c|c|c|c|}
\hline $\begin{array}{l}\text { Evaluation } \\
\text { domains }\end{array}$ & $\begin{array}{l}\text { Structured } \\
\text { feedback } \\
\text { after the } \\
\text { module } \\
\\
\text { (Mean } \\
\text { score } \pm \\
\text { SD) }\end{array}$ & $\begin{array}{l}\text { Anonymous } \\
\text { feedback } \\
\text { during the } \\
\text { module } \\
\\
\text { (Mean score } \\
\pm \text { SD) }\end{array}$ & p-value \\
\hline $\begin{array}{l}\text { Course } \\
\text { Content and } \\
\text { Organization }\end{array}$ & $\begin{array}{l}4.77 \pm \\
0.71\end{array}$ & $4.63 \pm 0.88$ & 0.19 \\
\hline $\begin{array}{l}\text { Student } \\
\text { Contribution }\end{array}$ & $\begin{array}{l}4.72 \pm \\
0.65\end{array}$ & $4.70 \pm 0.93$ & 0.84 \\
\hline $\begin{array}{l}\text { Learning } \\
\text { Environment } \\
\text { and } \\
\text { Teaching } \\
\text { Methods }\end{array}$ & $\begin{array}{l}4.84 \pm \\
0.77\end{array}$ & $4.82 \pm 0.65$ & 0.18 \\
\hline $\begin{array}{l}\text { Learning } \\
\text { Resources }\end{array}$ & $\begin{array}{l}4.86 \pm \\
0.83\end{array}$ & $4.88 \pm 0.54$ & 0.62 \\
\hline $\begin{array}{l}\text { Quality of } \\
\text { Delivery }\end{array}$ & $\begin{array}{l}4.75 \pm \\
1.10\end{array}$ & $4.79 \pm 0.87$ & 0.36 \\
\hline
\end{tabular}


Table 2: Comparison of qualitative data received in structured and anonymous feedback

\begin{tabular}{|l|l|}
\hline $\begin{array}{l}\text { Conventional } \\
\text { feedback } \\
\text { (Total comments } \\
\text { 25) }\end{array}$ & Anonymous feedback \\
\hline $\begin{array}{l}\text { Course Content } \\
\text { and Organization } \\
(4)\end{array}$ & Content Delivery (11) \\
\hline $\begin{array}{l}\text { Learning } \\
\text { Resources (10) }\end{array}$ & $\begin{array}{l}\text { Timetable / Resource } \\
\text { material/Learning resources (9) }\end{array}$ \\
\hline $\begin{array}{l}\text { Student } \\
\text { Contribution (1) }\end{array}$ & $\begin{array}{l}\text { Feedback on anonymous } \\
\text { feedback (6) }\end{array}$ \\
\hline $\begin{array}{l}\text { Learning } \\
\text { Environment and } \\
\text { Teaching } \\
\text { Methods (9) }\end{array}$ & $\begin{array}{l}\text { Acknowledgement/Appreciation } \\
(6)\end{array}$ \\
\hline $\begin{array}{l}\text { Quality of } \\
\text { Delivery (1) }\end{array}$ & $\begin{array}{l}\text { Feedback on formative } \\
\text { assessment (7) }\end{array}$ \\
\hline Feedback on summative \\
\hline assessment (18)
\end{tabular}

\section{DISCUSSION}

For continuous improvement in curriculum delivery, it is important to collect both quantitative and quantitative evaluation data to compare the quality of teaching sessions and the performance of the teaching faculty. According to our results, the quantitative data which was gathered through the official evaluation portal at the end of the module was statistically similar to the quantitative data collected anonymously in real-time during the entire duration of the module. Our findings are in contrast to the results of a similar study that compared anonymous and open evaluations for faculty by residents and medical students and showed lower evaluations on the anonymous feedback system [9]. Possible reasons for the difference in results could be the fact that the earlier study was conducted in both undergraduate medical students and residents and our study analysed evaluations of only undergraduate medical students.

According to our results, the number of comments received on the official evaluation portal was quite less in comparison to the data received on the anonymous unstructured portal. Students showed a tendency in the anonymous portal to include more details to provide feedback and evaluated the newly introduced learning strategies in a detailed manner. Evaluation relevant to content delivery, module organization and formative assessments was provided immediately on our anonymous portal; structured and standardized feedback might influence the originality, promptness and specificity of the comments. Standardized evaluation had only a few comments on changes incorporated during the module which indicates that students might forget to reflect on instructional strategies.

These findings are in agreement with an Australian study that reported that students are more likely to express their opinions anonymously in comparison to open communication systems [10]. Possible reasons for the low number of comments received on our official evaluation portal could be the fact that this data was collected at the end of the module and by the end of the four weeks module, students might have forgotten many things which they wanted to express. Another reason could be the fact that the official portal provided template and themes for students to respond to whereas many of the comments received on the anonymous portal belonged to the domains that could not have been created or anticipated by teachers while designing the structured evaluation questionnaire. Providing structured questionnaire to students to evaluate the course and faculty might restrict students from commenting on variables important to students. Another important factor that could have contributed to students being more expressive on the anonymous portal is easy accessibility for providing feedback throughout the module using digital gadgets; the incorporation of technology in education has been reported to be associated with increased performance and interest of students [11-13].

\section{CONCLUSION}

To conclude, anonymous and real-time feedback may help faculty to immediately resolve highlighted problems, ensure active participation and reduce the insecurities of medical students. Anonymous evaluation can influence the way the message is received and processed. 


\section{AUTHORS' CONTRIBUTIONS}

AS: Conceived and designed study; collected, analyzed and interpreted data; drafted manuscript. FA: Designed study; interpreted data and drafted manuscript, reviewed the final draft. KI: Designed study; analyzed and interpreted data; reviewed the final draft.

\section{REFERENCES}

[1] J. Morrison, Evaluation, $\mathrm{ABC}$ of learning and teaching in medicine, BMJ (Clinical research ed.) 326(7385), 2003, pp. 385-387. DOI:https://doi.org.10.1136/bmj.326.7385.385

[2] X.F. Yang, T. Talmy, C.H. Zhu, et al., Evaluation of Teaching and Learning: A Basis for Improvement in Medical Education, Chin Med J (Engl), 2017, 130(10), pp. 1259-1260. DOI:https://doi:10.4103/0366-6999.205851

[3] K.Z. Victroff, S. Hogan, Student's perception of effective learning experiences in dental school; a quantitative study using a critical incident technique, J Dent Edu, 2006; 70(2), pp. 124-132.

[4] H.W. Marsh, Students' Evaluations of University Teaching: Dimensionality, Reliability, Validity, Potential Biases and Usefulness, in: Perry R.P., Smart J.C. (eds) The Scholarship of Teaching and Learning in Higher Education: An Evidence-Based Perspective. Springer, Dordrecht, 2007, DOI:https://doi.org/10.1007/1-4020-5742-3_9

[5] T. Bergstrom, A. Harris, K. Karahalios, Encouraging Initiative in the Classroom with Anonymous Feedback, in: Campos P., Graham N., Jorge J., Nunes N., Palanque P., Winckler M. (eds) HumanComputer Interaction - INTERACT 2011. INTERACT 2011. Lecture Notes in Computer Science, vol 6946. Springer, Berlin, Heidelberg, 2011, DOI:https://doi.org/10.1007/978-3-64223774-4_49

[6] M. Iqbal, B. Khizar, Medical students' perceptions of teaching evaluations, The Clinical Teacher, 6, pp. 69-72. DOI:https://doi.org/10.1111/j.1743498X.2009.00268.x

[7] A. Shabbir, H. Raja, A.A. Qadri, et al., Faculty Feedback Program Evaluation in CIMS Multan,
Pakistan, Cureus, 2020, 12(6): e8612. DOI:https://doi:10.7759/cureus.8612

[8] R. Ahmed, Z. Naqvi, M. Khurshid, Results of faculty evaluation at the Aga Khan University, Karachi, Pakistan, J Pak Med Assoc, 1999, 49(6). Pp. 135139.

[9] N.M. Afonso, L.J. Cardozo, O.A. Mascarenhas, et al., Are anonymous evaluations a better assessment of faculty teaching performance? A comparative analysis of open and anonymous evaluation processes, Fam Med, 2005, 37(1), pp. 43-7.

[10] L.D. Roberts, C.J. Rajah-Kanagasabai, "I'd be so much more comfortable posting anonymously": Identified versus anonymous participation in student discussion boards, Australasian Journal of Educational Technology, 2013, 29(5). DOI:https://doi.org/10.14742/ajet.452

[11] F. Azam, A. Shaheen, K. Irshad, et al., Trends of undergoing formative assessment in undergraduate medical students, JSTMU, 2019, 1(1): pp. 21 -26.

[12] K. T. Brinko, The Practice of Giving Feedback to Improve Teaching, The Journal of Higher Education, 1993, 64(5), pp. 574-593, DOI:https://doi.org/10.1080/00221546.1993.11778 449

[13] M. Husain, S. Khan, Students' feedback: An effective tool in teachers' evaluation system, Int J Appl Basic Med Res, 2016, 6(3), pp. 178-181. DOI:https://doi:10.4103/2229-516X.186969 